\title{
Study on Thermal Performance Assessment of Solar Hot Water Systems in Malaysia
}

\author{
Shaharin Anwar Sulaiman ${ }^{1, \mathrm{a}}$ and Fariza Fansara Fauzi ${ }^{1}$ \\ ${ }^{1}$ Department of Mechanical Engineering, Universiti Teknologi Petronas, 31750 Tronoh, Malaysia
}

\begin{abstract}
Solar Hot Water Systems (SHWS) are gaining popularity in Malaysia due to increasing cost of electricity and also awareness of environmental issues related to the use of fossil fuels. The introduction of solar hot water systems in Malaysia is an indication that it has potential market. However, there is a need for a proper methodology for rating the energy performance of these systems. The main objective of this study is to assess the thermal performance of several SHWS subject to four different locations in Malaysia using combined direct measurement and computer modelling using the TRNSYS simulation program. The results showed distinct differences in performance of the systems as a result of locations and manufacturers. The findings could be used further in developing an acceptable rating system for SHWS in Malaysia.
\end{abstract}

\section{Introduction}

Utilization of solar energy for domestic or industrial water heating is attractive because of its environmental friendly feature as compared to fossil fuels [1]. The penetration of SHWS and the technologies into Malaysian market by several SHWS manufacturers or suppliers [2] is a welcome development. However, a methodology for assessing the thermal performance of these systems is required to ensure that they deliver the claimed energy savings and contribute significantly towards greenhouse gas emissions reduction. Until now, such a methodology has not been available locally; as such the claimed thermal performance of the systems by manufacturer cannot be independently verified.

This study is a preliminary attempt to look into such a methodology through evaluation of several SHWS available locally subject to different climatic conditions of Malaysia. In order to evaluate the thermal performance of the systems, the TRNSYS simulation program [3] was employed. This program was employed by Morrison and Tran [4] in carrying out energy rating of domestic water heaters in Australia. TRNAUS, the TRNSYS version adapted to Australian conditions [5] provides a means for rating electric, gas, solar and heat pump water heaters. However, this rating system cannot be implemented directly in Malaysia due to the different weather condition [6] as well as the characteristics of the system components which are different from one country to another. The objective of this work is to assess thermal performance of solar hot water systems in Malaysia as a preliminary steps prior to taking the approach developed in $[4,5]$.

\footnotetext{
${ }^{\text {a } C o r r e s p o n d i n g ~ a u t h o r ~: ~ s h a h a r i n @ p e t r o n a s . c o m . m y ~}$
}

This is an Open Access article distributed under the terms of the Creative Commons Attribution License 2.0, which permits unrestricted use, distribution, and reproduction in any medium, provided the original work is properly cited. 


\section{Method of Study}

The required parameters for SHWS were first gathered as the inputs to the TRNSYS in order to evaluate the system's thermal performance. The establishment of energy savings and greenhouse gas emissions reduction was then developed based on the calculated thermal performance.

\subsection{Data Collection}

In order to achieve a successful assessment of the systems' thermal performance using TRNSYS software, all the appropriate inputs need to be supplied. The data required were the performance characteristics of the solar collectors, tanks, pump, control strategy, weather, average monthly cold water temperatures, typical load profiles in main cities in Malaysia, etc.

\subsection{Mathematical Modelling}

Mathematical models are required to describe the system or component of a system by a set of variable and equation. For an example, for a conduction heat transfer (q) through an external wall of the solar storage tank, the variable taken into account were the thickness of the wall $(l)$, conductance of the wall $(k)$, inside temperature $\left(T_{i}\right)$, and outside temperature $\left(T_{o}\right)$. The mathematical models of all components involved have been developed and become parts of TYPE in TRNSYS [3]. The schematic of the systems being modelled is shown in Figure 1.

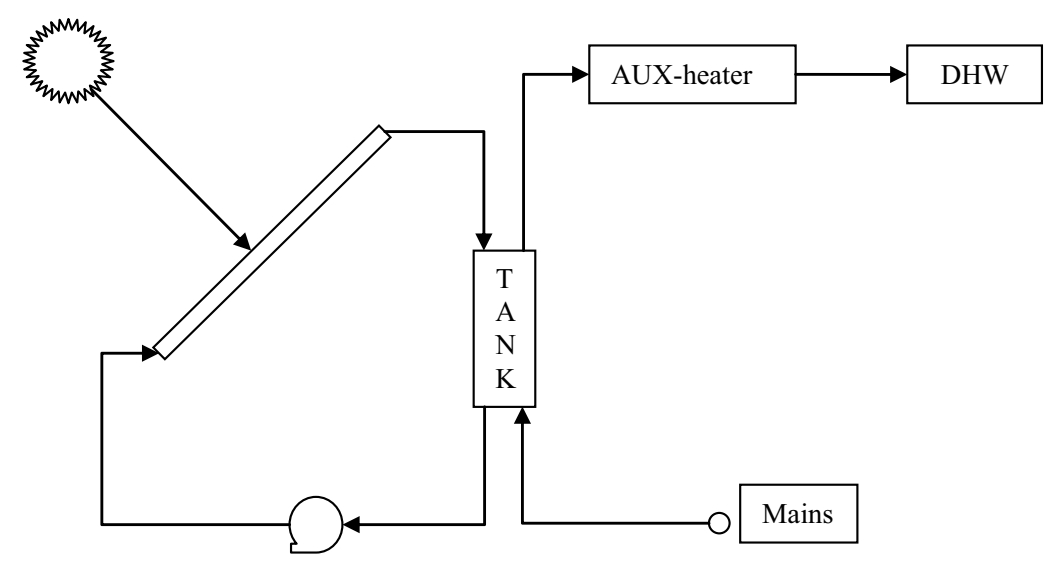

Figure 1. Schematic of the system. DHW: domestic hot water.

\subsection{TRNSYS Simulation Program}

TRNSYS is modelling package for transient simulation of energy systems [3]. It can be used to simulate systems from simple domestic hot water to the design and simulation of multi-zone buildings, the equipment and others. TRNSYS provides some components (called TYPEs) needed to simulate SHWS including solar collector, tank, heater, pump, etc. It also has components for the simulation outputs such as printer, integrator, etc. TRNSYS can read and process weather data of certain formats.

\section{Results and Discussions}

Thermal performance of the system was obtained from the SHWS configuration based on the simulation. Thermal performance of SHWS was defined by the auxiliary heat transfer rate that 
occurred within the storage tank boundary. The thermal performance of SHWS very much depended on the reliable input parameters that were employed into the TRNSYS software. There were four (4) different graphs obtained from the software; i.e. for the solar collector and storage tank.

Shown in Figure 2 is the variation of water temperature and heat transfer rate at the (a) inlet and (b) outlet, with time at the solar collector. In the figure, TiColl is defined as the inlet temperature for solar collector, and ToColl is the outlet temperature. GColl is the solar irradiance on the collector's surface and mdColl is the solar radiation. The average inlet water temperature for solar collector is shown to about $45.5^{\circ} \mathrm{C}$, while the average outlet water temperature is about $65.5^{\circ} \mathrm{C}$. As shown in the figures, the inlet and outlet temperatures vary daily depending on the weather condition at the location. The lowest inlet temperature recorded is $20^{\circ} \mathrm{C}$ while the highest is about $50^{\circ} \mathrm{C}$. The highest value of solar heat transfer rate is around $2500 \mathrm{Wh} /$ day, and the lowest value is around $600 \mathrm{Wh} / \mathrm{day}$. The average solar radiation at the solar collector was about $1700 \mathrm{Wh} /$ day.

(a)

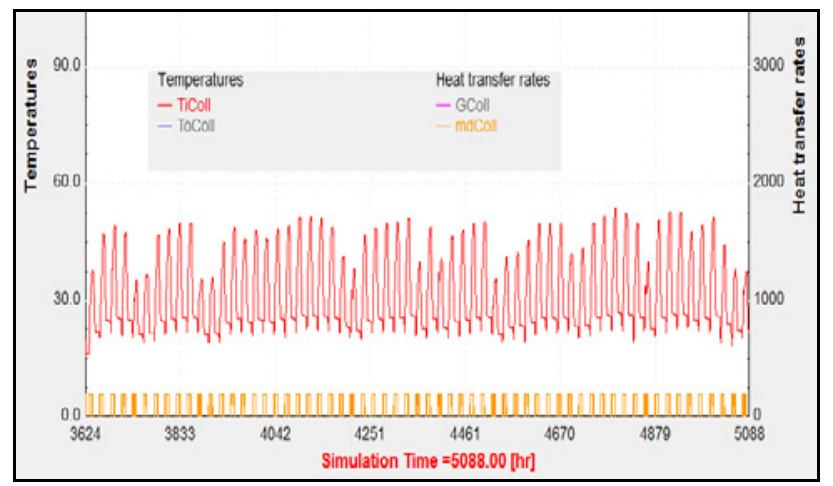

(b)

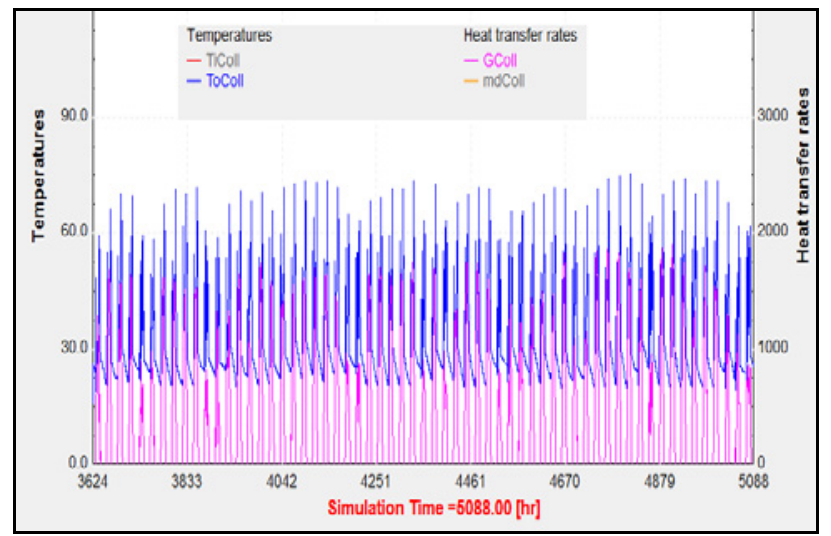

Figure 2. Temperature $\left({ }^{\circ} \mathrm{C}\right)$ and solar radiation (Wh/day) at (a) inlet and (b) outlet of solar collector.

Shown in Figure 3 is the variation of auxiliary heat transfer rate (i.e. make up power by electricity to overcome instant shortage in solar irradiation) for the storage tank. The average peak auxiliary heat transfer rate is shown to be around $4500 \mathrm{~W}$. The day-to-day auxiliary heat transfer rate is shown to fluctuate depending on the local solar radiation. The auxiliary heat transfer rate is inversely proportional with the solar radiation. In other words, the higher the solar radiation for a particular period of time, the lower would be the auxiliary heat transfer rate. The highest value of auxiliary heat transfer rate simulated in this work exceeded $6000 \mathrm{Wh} /$ day. 


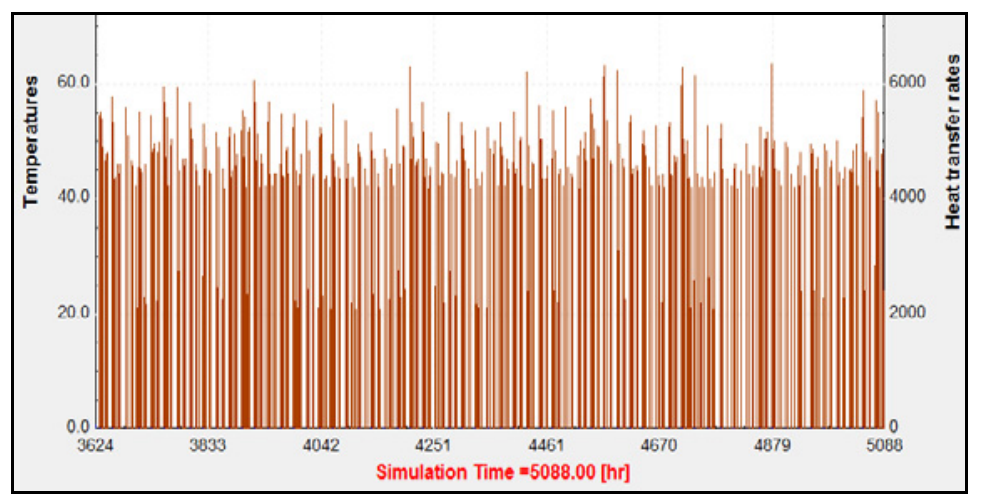

Figure 3. Temporal variation of auxiliary heat transfer rate $(\mathrm{Wh} /$ day) for the storage tank.

\section{Rating System for SHWS}

The main objective for this work was to assess the thermal performance of SHWS in Malaysia, which could lead to establishment of rating systems for solar hot water device. Based on the thermal performance study conducted using TRNSYS simulation above, the rating system of solar hot water is proposed. Thermal performance rating calculation method was used to calculate the annual energy savings and greenhouse gas emission reduction by using SHWS with a storage tank of a volumetric water of up to $300 \mathrm{~L}$ for domestic purposes. The annual energy savings for a SHWS was calculated by subtracting the energy used by the SHWS that deliver to the specified energy from the electrical energy consumption of an electric water heater which deliver the equivalent load. The calculation was performed for four different locations, for comparison using four different undisclosed manufacturers, identified only as Manufacturers A, B, C and D.

Using the auxiliary heat transfer rate value obtained from the TRNSYS Simulation Program, the system thermal performance was found to be $4.5 \mathrm{kWh} /$ day based on input energy load of $20.2 \mathrm{MJ} /$ day for small household within the city of Kuala Lumpur. The total auxiliary energy consumed for an SHWS in a year was calculated to be $1.644 \mathrm{MWh} /$ year.

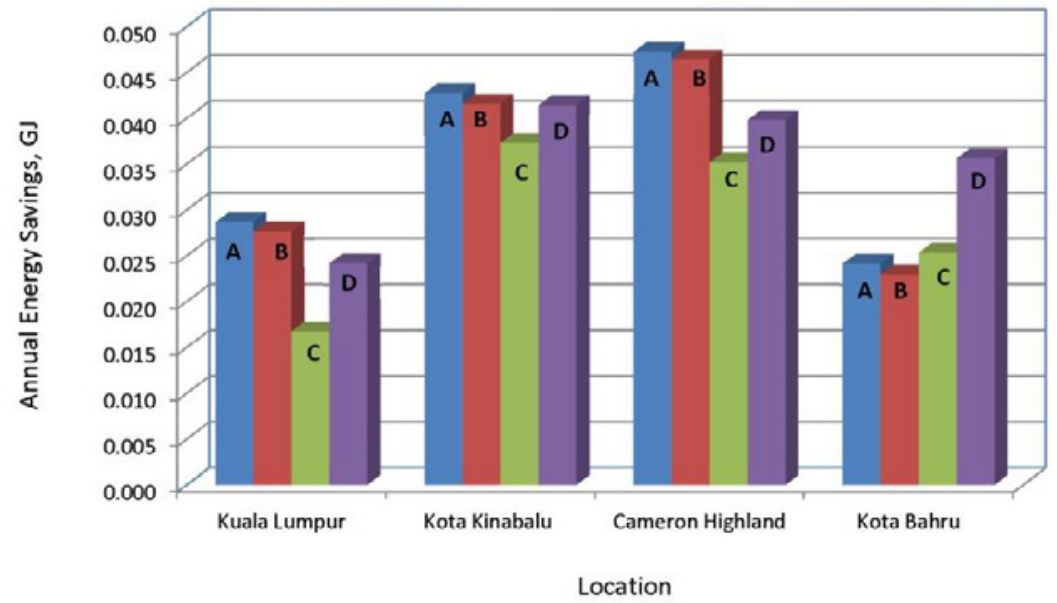

Figure 4. Annual energy savings (GJ) for different locations and SHWS manufacturers

The equivalent energy consumption for conventional electric water heaters of small capacity storage tank for Manufacturer A would be $2.44 \mathrm{MWh} /$ year. Thus, the energy savings by using SHWS was calculated to be $0.796 \mathrm{MWh} /$ year or $2.866 \mathrm{GJ} /$ year. In 10 years, the amount of energy that could 
be saved would be $7.96 \mathrm{MWh}$. Not only the amount of energy saving by using the SHWS (against electric water heaters) would be huge, the amount of greenhouse gas emissions reduction would be expected to be significant. The same calculation method was carried out for three other locations, i.e. Kota Kinabalu, Cameron Highlands and Kota Bahru. Their annual energy savings are shown in Figure 4. SHWS could be rated by several schemes based on their thermal performance as well as by the energy savings and the greenhouse gas emission reduction for each system. The comparative performance information shown in Figure 4 clearly differentiates the qualities of SHWS produced by different manufacturers in relation to energy savings.

The proposed rating systems for solar water heater could be used in developing a guideline to manufacturers or suppliers in producing appropriate and competitive SHWS that would lead to green environment. By doing so, the amount of energy savings through the use of solar energy (in replacement of electricity) could be quantified. This assessment method will also help the consumers to assess the economic feasibility of any SHWS that they are considering buying.

\section{Conclusions}

This report discussed about the proper rating system for SHW in order to quantify the overall energy savings used. In order to develop this rating system, a study on thermal performance assessment of SHWS in Malaysia is required. Although the proposed thermal performance rating calculation method has not been certified and endorsed by Malaysian government, yet the development of this rating method is the first and crucial step that leads to minimize the energy performance of the SHWS itself. The proposed thermal performance rating method will also help to quantify the energy savings and greenhouse gas emissions reduction of the system. Different location and systems characteristics will lead to the different result of thermal performance. This is due to the weather condition of the particular location that been assessed as well as the efficiency of the system itself. This shows the importance of the proposed thermal performance rating method discussed in this report. The proper thermal performance rating produced will be used to provide helpful information to consumers, in order to verify the claimed energy performance and greenhouse gas emissions reduction of the system, to provide basis for comparison of greenhouse impact of all forms of water heating appliances in Malaysia as well as to provide the references and guidelines for supporting program.

\section{Acknowledgement}

The authors would like to express their appreciation to Dr. Edward Halawa of Charles Darwin University, Australia, for his support and comments.

\section{References}

1. Planning and Installing Solar Thermal Systems - A Guide for Installers, Architects and Engineers, James \& James, UK (2005).

2. E. Halawa in ASEAN, WASET Conference, Bangkok, (2011).

3. TRNSYS 16-A Transient System Simulation Program, Solar Energy Laboratory, University of Madison, USA (2005)

4. G.L. Morrison, H.N. Tran, Energy Rating of Domestic Water Heaters, ANZES 1992 Annual Conference, Darwin (1992)

5. G.L. Morrison, TRNAUS 14.1 - TRNSYS Extensions for Solar Water Heating 92014 http://users.tpg.com.au/t_design/Trnaus/TRNAUS.pdf

6. B. Ali, K. Sopian, M. Al Ghoul, M.Y. Othman, A. Zaharim, A.M. Razali, Eur J of Sci Res, 26, 20-28 (2009) 